\title{
EL BOLETÍN DE LA INSTITUCIÓN LIBRE DE ENSEÑANZA B.I.L.E.
}

\author{
Eulalia Martínez Medrano \\ Universidad de la Rioja
}

RESUMEN. En este artículo presento un análisis descriptivo del Boletín de la Institución Libre de Enseñanza en sus dos épocas de existencia. . Períodos delimitados por los acontecimientos de nuestra guerra civil.

La PRIMERA es la más importante por su duración, abarca sesenta años de publicación ininterrumpida, desde el año 1877 hasta la mitad de 1936.

La SEGUNDA época del B.I. L.E, es relativamente reciente, reaparece en 1987 y lo edita la Fundación Francisco Giner de los Ríos.

El revisar que misión se propuso esta revista, sus comienzos, evolución y estructuras contribuirá al convencimiento de que el Boletín constituye una fuente documental valiosísima e imprescindible para el estudioso de la Institución Libre de Enseñanza y también para quien quiera profundizar en la evolución de la Historia de la Educación Española de finales del siglo XIX y comienzos deL XX.

Especialmente es fuente necesaria para conocer nuestra incorporación al Movimiento Pedagógico de la Escuela Nueva, directrices educativas que fueron seguidas por la I.L.E y de cuyos principios y realizaciones ha quedado constancia en las páginas de su Boletín.

ABSTRACT. In this article, I show a descriptive analysis about Teaching Free Institution Bulletin in its two periods, such periods are delimited by our Civil War Events.

The first period is the most important due to its duration, is extended to sixty years of continued publication from 1877 to the middle of 1936.

The second period of this Bulletin, is relatively recent, reappears in 1987 and it is edited by Francisco Giner de los Ríos Foundation.

Revising the aim of this magazine, its beginnings, evolution and structure will contribute to the convinction that this Bulletin is considered a very important and imprescindible source for the study of Teaching Free Institution and in the same way, for people who wants to deepen in the evolution of Spanish Education history from the ending of 19th century to the beginning of 20th century.

It is specially a necessary source to know our incorporation to New School Pedagogy Movement,educational guidelines, which were followed by Teaching Free Institution and whose principles and realizations had placed the pages of this Bulletin on record.

\section{Introducción}

Sin duda la corriente pedagógica más importante de finales del siglo XIX y principios del XX español, la que ha dejado huellas profundas en la vida nacional a través de tres generaciones, es la influencia ejercida por la Institución Libre de Enseñanza (I.L.E.) 
La Institución surge por la acción de un grupo de profesores universitarios que se habían formado en el espíritu Krausista, filosofía que introdujo en España J. Sanz del Río y que expuso y difundió a través de su cátedra y de sus publicaciones.

Este grupo de profesores, seguidores de la nueva ideología liberal y progresistas se ven envueltos en vicisitudes profesionales desagradables; son separados de su cátedra en 1865 en el período de la Primera Cuestión Universitaria y siguiendo el vaivén de los acontecimientos histórico-políticos del momento, se les restituye a sus cargos o se les exilia, según el partido político imperante como más representativos recordaremos a Salmeron. Azcarate y Giner de los Ríos.

En 1876 y coincidiendo con la nueva Constitución, deciden abrir una universidad libre con el capital aportado por unos quinientos accionistas a la que denominan Institución Libre de la Enseñanza.

De la lectura de sus estatutos podríamos concluir que se proponen un doble campo de acción: el fundamental que es la creación de un centro de enseñanza que abarca tres niveles educativos e influir en otros sectores de la vida nacional, guiados siempre por su filosofía impulsora de un movimiento intelectual, pedagógico y europeísta.

El alma de la Institución es Dn. Francisco Giner de los Ríos cuyo ideal es lograr una renovación de la vida española. Estaba convencido que no bastaban las leyes, ni la política, había que llegar al hombre y el hombre se forja por medio de la educación. La palanca de una sociedad, nos dirá que son sus individuos integramente educados . Tenía fe en la acción de un hombre sobre otro hombre y concebía la educación como una captación plena del hombre por el ideal. Estamos ante una influencia del Krausismo representada por los teóricos como Sanz del Río, Fernando de Castro Azcarate y otros que se agrupan constituyendo una vertiente realista liderada por Giner, Dn Francisco es el práctico el que sintetiza en su programa de la I.L.E. la filosofía o teoría con la realización educativa.

La Pedagogía de la Institución se fundamenta en una educación integral, neutra, activa, unificada, gradual, en régimen de coeducación y abierta al entorno cultural y natural. Tiene como finalidad la formación completa del hombre en todos sus aspectos de ahí que sus objetivos sean lograr una Educación intelectual. estética, moral, social y física. El institucionista es un hombre culto y responsable.

Son realizaciones características de la Institución entre otras, la asociación de antiguos alumnos, las colonias escolares, las excursiones, la biblioteca circulante, el B.I.L.E., la fundación Francisco Giner y para terminar cito las misiones pedagógicas debido al impulso del riojano M.B. Cossio, aspiración que se ve cumplida en 1931. Las misiones constituyen un esfuerzo entusiasta para llevar la cultura a los ámbitos rurales más recónditos de España.

\subsection{Origen y objetivos del B.I.L.E.}

La real orden de 16 de Agosto de 1876 autoriza los Estatutos de la Institución Libre de Enseñanza, los cuales habían sido ya aprobados interinamente por la Junta General de Señores Accionistas, el día 31 de Mayo del mismo año, llevan la firma del Primer Presidente,D Laurence Figuerola. 
Se dividen en dos partes: la primera titulada de" La Asociación" , abarca un total de catorce artículos. La segunda titulada de "La Institución" comprende desde el artículo quince al diecinueve, y es aquí en el artículo dieciséis donde encontramos el germen del BOLETÍN DE LA INSTITUCIÓN LIBRE DE ENSEÑANZA (B. de la I.L.E.) o (B.I.L.E).

ARTICULO DIECISÉIS "La Institución establecerá según lo permitan las circunstancias y los medios de que pueda disponer:

1 ㅇ "Estudios de cultura general" ( o de segunda enseñanza) y profesionales con los efectos académicos que le confieren las leyes del Estado".

$2^{\mathrm{o}}$ "Estudios superiores científicos".

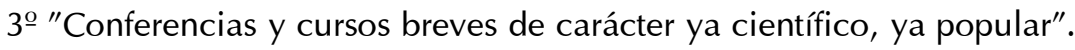

4 o "Una biblioteca y gabinetes de experimentación dotados de material correspondientes".

5 o "Un boletín para publicar sus documentos oficiales y trabajos científicos".

60 "Concursos y premios y cuanto contribuya al promover la cultura general y sus propios fines". (1)

Transcribo íntegro el artículo quince porque será el que sirva de introducción a todos los números del BILE indicando con esta cita textual los principios ideológicos en que se asienta la publicación.

ARTICULO QUINCE. "La Institución Libre de Enseñanza es completamente ajena a todo espíritu e interés de comunión religiosa escuela filosófica o partido político; proclamando tan solo el principio de la Libertad e inviolabilidad de conciencia, y de la consiguiente independencia de su indagación y exposición respecto de cualquier otra autoridad que la de la propia conciencia del Profesor, único responsable de sus doctrinas

Después de haber dado al BILE una existencia legal con la revisión de los Estatutos es inmediata la pregunta:)Qué es el Boletín de la I.L.E.? Justamente un juicio objetivo y completo es lo que intentamos conseguir con este artículo, y también con la acertada opinión de personas especializadas en el estudio de la Institución.

El Primer Director del Boletín, Don Francisco Giner, hace un breve resumen de su contenido al teminar el primer año de su publicación:

"Consta de trabajos originales de los profesores de la institución, obras experimentales y obras teóricas sobre las diversas ciencias".

"También ofrece crítica de libros y las investigaciones más importantes que sobre asuntos científicos ven la luz dentro y fuera de España".

"Hay estractos de las lecciones del mayor número posible de cursos superiores de la Institución y especialmente aquellos que no se explican en ningún otro centro oficial o privado..."

“...Puede disponer el lector, de catálogos de los gabinetes de la Institución, especialmente en la parte que presentan mayor interés científico, tales como colecciones geológicas de comarcas españolas, preparaciones y fotografías microscópicas". (2)

Joaquín Costa, por el año 1887 residía en Huesca e inició la publicación de una serie de artículos en la prensa de esta Capital donde exponía la misión de la Institución así como la importancia de su Revista. Emitía este juicio de valor: 
"Por sus dimensiones, el Boletín, es el Gulliver del periodismo; pero un Gulliver de diamantes" (3)

La autora Ivonne-Turín dice: "La mejor fuente actual para seguir el desarrollo de la I.L.E. es el Boletín de la Institución. Esta Revista tiene el defecto de ser un poco seca y de contener sobre todo indicaciones ADMINISTRATIVAS.Los hombres, las personalidas se hallan esfumados tanto más cuanto que la revista no era de las que se dejan llevar de disgresiones inútiles" (4)

Vicente CACHO VIU dice: "Aparece por vez primera el día 7 de marzo de 1877 y la dirige don Francisco Giner. Tipo de letra pequeño, pero claro. Al frente de la página primera figura del artículo quince" (5)

En la Junta General de Señores Accionistas correspondiente al curso Académico 1926-27, se dedican unos momentos a evocar su CINCUENTENARIO y con palabras sencillas, el Señor Secretario indica la vinculación de la Institución con su Boletín y viceversa.

"El Boletín cumple también en este año su primer cincuentenario.En sus columnas se ha reflejado constantemente la vida de la I.L.E. y con ella quisiéramos que siguiera viviendo, como uno de los órganos de expansión de la obra" (6).

Finalmente con motivo del Centenario de la Institución, 1977, la Revista Educación publica un número monográfico sobre la institución Libre de Enseñanza y emite un juicio sobre el Boletín:

“...A través del B.I.L.E. penetra en nuestro país información respecto a los problemas de educación en el mundo, debates pedagógicos, propuestas de reforma del sistema educativo, bases de discusión sobre el papel del Estado y la Sociedad en la organización de la Enseñanza. (7)

\subsection{Evolución del B.I.L.E en su primera época.}

El B.I.LE. se edita durante sesenta años ininterrumpidamente (1877-1936), su evolución es un continuo IN CRECENDO.

El primer número del Boletín aparece el día siete de marzo de 1877, al año de haberse fundado la Institución. Los números del primer año se tiran de forma irregular en cuanto a fechas, siguiendo siempre las necesidades de la incipiente organización de la I.L.E.

Se publica en la sede de la Institución, calle de Esparteros número 9, principal (Madrid). El contenido se dispone a dos columnas y oscila entre cuatro y cinco páginas en este primer período.

Al final del año II pasó a ser quincenal con un total de ocho páginas. La suscripción costaba cuatro pesetas, pero luego paso a cinco y podía adquirirse en todas las librerías. También se hicieron publicaciones por tomos.

Al final de una reseña del Boletín, en la contraportada del Tomo correspondiente a los años 1878-79 se lee esta frase: "ESTA PUBLICACIÓN ES LA REVISTA CIENTÍFICA MÁS BARATA DE ESPAÑA".

En el año quinto de la Revista, correspondiente a 1881 el último número tiene ya doce páginas y la reseña dice así: 


\begin{abstract}
"Ve la luz dos veces al mes en número de veinticuatro columnas y contiene=revistas de cultura general con extractos de las publicaciones especiales, artículos científicos, literarios y pedagógicos; investigaciones originales de los profesores; crítica de libros y trabajos importantes, españoles y extranjeros ; resumenes de las enseñanzas dadas en la Institución; excursiones hechas por los alumnos; catálogos de los gabinetes y bibliotecas de la Institución y noticias referentes a las mismas .
\end{abstract}

Sigue teniendo el precio de cuatro pesetas para los socios y el doble para el público.

En el año VIII del Boletín, correspondiente al tomo VIII del año 1883, se lee que el Boletín sigue siendo quincenal, como veníamos consignando en los años anteriores pero ahora llega a las treinta y dos columnas= dieciséis páginas. Su contenido es análogo pero los precios han variado algo.

La suscripción anual es de 5 ptas para los socios , 10 para el público, y 20 para los suscriptores de América y Extranjero.Cada número vale 0,50 ptas.Los tomos sueltos son al precio de 7,5 ptas para los socios y 15 para el público.

Se pone a la venta una colección encuadernada de siete tomos de Boletín en SEIS VOLUMENES, porque el volumen segundo abarca los tomos II y III incompletos. El precio de esta colección asciende a 30 ptas para los socios y a 50 para el público.

Así continua hasta el 1893, tomo XVII que en el mes de Junio se convierte en mensual y pasa a tener 32 páginas

En el año 1902, en la contraportada última se lee: "Se publica una vez al mes en número de 64 columnas y contiene: Estudios y Revistas Pedagógicas, artículos científicos y de carácter popular sobre diversas esferas de la cultura; crítica de los libros y trabajos importantes españoles y extranjeros; resumenes de excursiones hechas por los alumnos y de las enseñanzas de la Institución; catálogos de las colecciones, y noticias referentes a la misma" (8)

Pasamos a la última reseña publicada, que es la correspondiente al año 1935. Dice textualmente :"Se publica esta revista una vez al mes en número de sesenta y cuatro columnas"

La suscripción anual en la península es de 10 ptas para los antiguos suscriptores y 12 ptas para los nuevos.

En América y Extranjero son 20 ptas. Los números sueltos se venden a 1 ptas. Tomo suelto 15 pesetas. La colección encuadernada que consta de 55 volumenes, es a 315 ptas. La Dirección anuncia también un índice de autores que comprende desde 1877 a 1926 por el precio de 5 pesetas.

Para finalizar consigno que en 1936 se dispone del Tomo LIX que es el correspondiente a 1935 y el tomo LX y último que recoge lo publicado en 1936, fecha en que cesa la publicación por causa de la guerra civil.

Con el número 920 del Boletín de la I.L.E. correspondiente a Diciembre de 1936 tomo LX, se cierra la revista y en el inserta la dirección la siguiente nota:

"Con este número de Diciembre termina el tomo LX del Boletín y la reimpresión del Tomo II del mismo. Sintiéndolo profundamente la I.L.E se ve obligada a suspender su publicación mientras dure la situación anormal porque atraviesa nuestro país . 
Existe para ello no sólo razones de índole económica, que no es posible dejar de tener presentes, sino también las dificultades insuperables en los actuales momentos de hacer llegar nuestra revista a manos de gran número de nuestros suscriptores."

"Cuando las dolorosas circunstancias cesen, ( y ojála , para bien de España y de todos sea en plazo breve!reanudaremos con la publicación de nuestro Boletín las relaciones de amistad y convivencia espíritual que, gracias a él hemos sostenido durante tantos años con nuestros suscriptores de España y del Extranjero. (9)

Este deseo de continuidad se ha cumplido; después de cincuenta años, el Boletín de esta Nueva época aparece en marzo de 1987.

\subsection{Otros Datos: Directores, Secciones y Colaboraciones.}

\section{DIRECTORES.}

Figuran como Directores a lo largo de la Historia del Boletín de la Institución y en su primera étapa los siguientes señores:

D.Francisco Giner de los Ríos, que se encarga de la publicación desde el 1877, fecha de la fundación de esta revista, hasta 1881.

D. Joaquín Costa que ostenta la Dirección desde 1881 a 1884, sucediéndole Caso Blanco.

El Señor Caso Blanco permanecerá en el cargo hasta 1889 fecha en que de nuevo pasa a regentar el BILE Giner de los Ríos, hasta el año 1904 que es relevado por Ricardo Rubio (10)

Ricardo Rubio es el que estará más años, aunque no consecutivos, desempeñando este puesto. Tiene una primera regencia desde 1904 a 1910 y otra desde 1917 al 1933.

Adolfo González Posada será director desde 1910 a 1917, y nuevamente ocupará el cargo Rubio.

Parece que al quedar el Sr. Rubio imposibilitado, por pérdida notable de su visibilidad, pasó a encargarse del Boletín el Sr. Don José Ontañón, que era profesor de la I.L.E., puesto que desempeñó hasta la suspensión del Boletín , en 1936.

En la memoria de Secretaría leída en la junta general ordinaria de señores accionistas celebrada el día veintisiete de mayo de 1935 se lee la reseña de la cooperación de Ricardo Rubio y con palabras de dolor se comunica su pérdida. Allí se dice:

"que ha pocos años se vió obligado a abandonar la Dirección del Boletín por causa de pérdidad de la vista... Y aunque de la falta de salud y de fuerzas le obligaron a abandonarla procuraba estimular a los que le reemplazaron con todos los medios que estaban a su alcance..." (11)

\section{SECCIONES.}

En el Tomo XI del año 1987 el programa de la Revista comprendía tres grandes titulares y un índice alfabético de autores . Una parte era EDUCACIÓN Y ENSEÑANZA, otra ENCICLOPEDIA y otra INSTITUCIÓN.

De las tres secciones la más importante para conocer la vida de la Institución y la que más claramente manifiesta que junto al carácter científico, el Boletín tenía un carácter oficial y sobre todo un sentido humano y de relación, es la tercera INSTITUCIÓN. 
El Boletín viene a ser un vínculo entre los socios miembros y simpatizantes de la I.LE. Recoge acontecimientos tan humanos como fallecimientos, donativos para remediar alguna necesidad de familiares o estudiantes de la Institución, relaciones de becas, viajes al extranjero, correspondencia, noticias a los alumnos etc.

Son apartados fijos de esta Sección los siguientes: sección oficial, memoria de la junta general de señores accionistas, notas de la Secretaría leídas en las Juntas ordinarias y extraordinarias, presupuestos y cuentas de ingresos y gastos generales, colonias escolares, asociación de antiguos alumnos, fundaciones, y sobre todo la sección, titulada in MEMORIAM, que es el recuerdo dedicado a los miembros desaparecidos, biografías interesantísimas que nos permiten conocer el espíritu, dedicación y entrega que tenían los miembros de la Institución.

En el Tomo XIII correspondiente a 1889 varían en algo los titulares pero no esencialmente.Se denominaran: PEDAGOGÍA, ENCICLOPEDIA, INSTITUCIÓN

\section{COLABORACIONES.}

En las páginas del Boletín encontramos colaboraciones de autores nacionales y bastantes firmas extranjeras. Son profesores y especialistas de gran relevancia en el campo científico, pedagógico, humanístico jurídico y artístico .

Nombres como Rafael Altamira, Gurmesindo Azcárate, Francisco Giner de los Ríos, John Dewey, E. Clapared, Oviedo Decroly, M.Bartolomé Cossio, Domingo Barnes, José Ontañón, Adolfo Posado, Ricardo Rubío y otros.

De la totalidad de colaboraciones que aparecen en sus indices y que son más de cuatro mil, el mayor número se registra en la sección de pedagogía siguiendo en importancia la sección tituladada Enciclopedia y en tercer lugar la referente a la Institución.

\section{El BILE en la Actualidad.}

Al terminar la guerra civil , la Institución Libre de Enseñanza fue considerada ilegal por Decreto del 17 de Mayo de 1940 y en consecuencia sus bienes fueron adscritos al Ministerio de Educación Nacional, patrimonio que no será devuelto hasta 1985. Durante estos años de anonimato, el espíritu de Giner y de la I.L.E sigue vivo, a pesar de las dificultades de todo tipo, no sólo económicas. Podríamos recordar Londres donde reside Natalia Cossio que sigue vinculada a otros miembros de la Institución París, Madrid y sobre todo México, donde se llega a crear la Asociación de Antiguos Alumnos de la I.L.E. promotora de una gama de actividades entre ellas la publicación de su Boletín. A nadie puede extrañar este florecimiento dado el gran número de exiliados que coincidieron en esta capital entre ellos D. Bernardo Giner de los Ríos.

En Abril de 1962 se reune y estructura la composición del Patronato Francisco Giner de los Ríos a la que siguieron otras reuniones en años siguientes. En Junio de 1977 la Fundación es reconocidad legal , y los patronos con gran entusiasmo y eficacia inician LOS TRÁMITES ADMINISTRATIVOS PARA RECLAMAR LA DEVOLUCIÓN de sus bienes, tarea ardua y llena de vicisitudes que finalizará en 1985 . 
Paralelamente a esta tarea burocrática se planificaban futuras tareas culturales; en 1979 se crea nuevamente la Asociación de Antiguos Alumnos de la I.L.E., se vuelven a iniciar las Colonias Escolares y por fin en 1987 a los cuarenta años de cierre (1936) y a los ciento diez de su primera aparición (1977) el Boletín de la Institución Libre de Enseñanza vuelve a publicarse editado por la Fundación Francisco Giner de los Ríos y en la sede primitiva de la Institución C. Martínez Campos 14.

En la presentación que figura al frente del primer número y con el título Al iniciar una nueva étapa figuran estas palabras". . . los años pasados nos han afianzado más en los principios inspiradores de nuestra institución y de su boletín, que ahora se renuevan; respeto máximo a la persona humana, a sus ideas religiosas, filosóficas, políticas o de cualquier otra índole, reconocimiento de la función educadora como agente de todo progreso duradero y vehículo de la cultura, cuyo fin primordional consiste en el máximo desarrollo de los grandes valores del espíritu humano".

Para la consecución de estos objetivos y en la medidad de nuestras limitadas fuerzas el Boletín de la Institución Libre de Enseñanza inicia hoy su nueva andadura. (12)

El Primer número aparece con las siguientes secciones: educación, enciclopedia, crónica, institución y bibliografía. Como puede apreciarse el formato es similar al BILE de la época anterior. Este formato , varia en el primer número del año 1990, que presenta el siguiente índice: artículos, crónica y reseñas.

Vuelve a manifestarse cual es el próposito de la BILE a partir de este número que no es otro que ofrecer a los lectores textos de autores representativos de la España nueva intelectual, cuya voluntad innovadora está muy consciente de sus raíces morales y espirituales. La aspiración máxima es acercarse al lector que no ha frecuentado hasta ahora sus páginas,... se aspira a considerar asuntos españoles y universales de particular relevancia para nuestro tiempo.

\section{Referencias Bibliográficas}

(1) B.I.L.E.núm 920-Diciembre 1936-Tomo XL-pág.138

(2) GINER DE LOS RÍOS, B.I.L.E.Tomo I (1877) (contraportada)

(3) COSTA, Joaquín, Diario de Huesca, día 19 y 22 de septiembre de 1887, 3,4.

(4) IVONNE-TURIN, La Educación y la Escuela Española de 1874-1902.Trad. por HERNÁNDEZ RUIZ, Madrid, Ed Aguilar, 1967, pág179.

(5) CACHO VIU, Vicente, La Institución Libre de Enseñanza , Ed. Rialp, Madrid, 1962 pág. 425.

(6) El cincuentenario de la Institución Libre de Enseñanza B.I.L.E., Tomo. I (1926) 168 y 192.

(7) EDITORIAL, Revista de Educación, Edit. Servicio de Publicaciones del M.E.C., Tomo.XXIV, (1976). Marzo -Abril, 3.

(8) B.I.L.E. núm 513-Contraportada-Diciembre de 1902.Tomo XXVI.

(9) B.I.L.E. núm 920-Diciembre 1936. (pág. 265). Tomo LX- (inacabado)

(10) B.I.L.E. núm 830-Tomo LIII -año 1929-pág. 186.

(11) B.I.L.E. núm 920-Diciembre 1936-Tomo XL pág .138.

(12) BOLETíN DE LA INSTITUCIÓN LIBRE DE ENSEÑANZA N11-Segundo Época. Año I. Madrid-Marzo 1987. 